\title{
Analyzing stakeholders' workshop dialogue for evidence of social learning
}

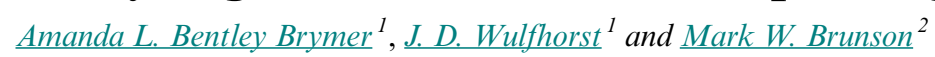

\begin{abstract}
After much debate and synthesis, social learning scholarship is entering an era of empirical research. Given the range across individual-, network-, and systems-level perspectives and scales, clear documentation of social learning processes is critical for making claims about social learning outcomes and their impacts. Past studies have relied on participant recall and concept maps to document perceptions of social learning process and outcome. Using an individual-centric perspective and importing ideas from communication and psychology on question-answer learning through conversational agents, we contribute an expanded conceptual framework and qualitative analytical strategy for assessing stakeholder dialogue for evidence of social learning. We observed stakeholder dialogue across five workshops coordinated for the Bruneau-Owyhee Sage-Grouse Habitat Project (BOSH) in Owyhee County, Idaho, USA. Participants' dialogue was audio recorded, transcribed, and analyzed for cross-case patterns. Deductive and inductive coding techniques were applied to illuminate cognitive, relational, and epistemic dimensions of learning and topics of learning. A key finding supports our inclusion of the epistemic dimension and highlights a need for future research: although some participants articulated epistemic positions, they did not challenge each other to share sources or justify factual claims. These findings align with previous research suggesting that, in addition to considering diversity and representation (who is at the table), we should pay more attention to how participants talk, perhaps prompting specific patterns of speech as we endeavor to draw causal connections between social learning processes and outcomes.
\end{abstract}

Key Words: Bureau of Land Management; communication; decision making; dialogue; public lands; social learning

\section{INTRODUCTION}

Diverse and conflicting interests in the use and management of natural resources and public lands are increasingly addressed through public planning and decision making (Reed 2008, Scarlett and McKinney 2016). In situations where there is a high degree of persistent change, complexity, interconnectedness, and uncertainty, managers and decision makers are faced with challenges of information, communication, coordination, and action (Scarlett 2013). To address some of these challenges, conventional practice among administrative agencies in systems of democratic governance is to scope an issue and gather comments prior to a final decision. Although these steps require "appropriate public participation" for the administrative change in question, they render any subsequent learning moot and management inflexible as the environment continues to change (Craig and Ruhl 2014).

In pursuit of more effective ways to gather information, make decisions, and adapt their actions, some agencies now seek to integrate science and policy making while promoting stakeholder collaboration and learning through various adaptive and collaborative management models (see McFadden et al. 2011, Rist et al. 2013a,b, Susskind et al. 2012, Scarlett 2013 for critical reviews). This shift from scoping-style public participation to learning and collaboration is driven in part by claims that discussion-based processes lead to positive outcomes like trust building and improved relationships for continued coordination (Buck et al. 2001, Schusler et al. 2003). However, negative outcomes of public participation like derailment and polarization have also been observed (Walker and Hurley 2004). Managers who respond to persistent change and complexity by adjusting their decision-making approach may find themselves "handcuffed" by burdensome participatory processes and disruptive litigation (Scarlett 2013, Craig and Ruhl 2014). Once considered hallmarks of administrative law, public participation and judicial review are now viewed as both values and obstacles to effective decision making and management (Craig and Ruhl 2014).

Scholars and practitioners can begin to overcome such obstacles by paying closer attention to four requirements for collaborative adaptive management: (1) establishment of clear goals and objectives, (2) mechanisms for promoting participation, (3) clear roles and processes for shared learning, and (4) the dynamic management of the adaptive management programs themselves (Susskind et al. 2012, Scarlett 2013). Regarding clear roles and processes for shared, or "social" learning, scholars must examine theoretical claims about the processes and outcomes of learning itself before concluding that such a requirement for public participation is beneficial (or detrimental) to decision making. Each management paradigm emphasizes the importance of learning as a process within processes of decision making and governance, yet we know little about its mechanisms and design in these social-ecological contexts (Fabricius and Cundill 2014). It is time to zoom in on learning as a process with conversational agents and mechanisms that present opportunities for change in understanding, and to explain how the nature of those mechanisms and changes relate to certain outcomes.

To this scholarly space we contribute an analysis of stakeholder dialogue about a social-ecological impact assessment for public lands in southwestern Idaho. Our purpose was to document social learning in deliberative workshop settings by examining participants' statements and question-answer exchanges for evidence of social learning, defined as a change in understanding in and between individuals in a group setting. This definition represents the first stage of a social learning process defined by 
Fig. 1. Adapted from Schusler et al. (2003) and integrates concepts from Blackmore (2007), Conley and Moote (2003), Muro and Jeffrey (2008, 2012), Reed et al. (2010), and Rodela (2011). Illustrates the process conditions that enable individual-level social learning, which generates new knowledge and understanding that can contribute to multiple outcomes at individual, network, and system scales.

\begin{tabular}{|c|c|c|c|}
\hline \multicolumn{2}{|c|}{ Deliberative Process enables } & & $\begin{array}{l}\text { System outcomes } \\
\text { Supportive policy, } \\
\text { structure }\end{array}$ \\
\hline \multirow{8}{*}{$\begin{array}{l}\text { Democratic structure } \\
\text { Diverse participation } \\
\text { Multiple sources of } \\
\text { knowledge } \\
\text { Facilitation } \\
\text { Dialogic interactions } \\
\text { Constructive conflict } \\
\text { Systems thinking }\end{array}$} & \multicolumn{2}{|c|}{ Social Learning generates } & state \\
\hline & \multirow{7}{*}{$\begin{array}{l}\text { Communication of cognitive } \\
\text { relational, and epistemic } \\
\text { positions } \\
\text { Opportunities for cognitive, } \\
\text { relational, and epistemic } \\
\text { change } \\
\text { A change in understanding }\end{array}$} & Knowledge contributes to & Network outcomes \\
\hline & & \multirow{6}{*}{\begin{tabular}{|l|l} 
Facts, values \\
Problems, opportunities \\
Disagreement, consensus \\
Alternative actions, potential \\
impacts \\
Opportunities to work \\
together \\
Other ways of knowing
\end{tabular}} & Collaborative relationships \\
\hline & & & Adaptive capacity \\
\hline & & & Change in resource use or \\
\hline & & & \\
\hline & & & $\frac{\text { Individual outcomes }}{\text { Common ground, purpose }}$ \\
\hline & & & $\begin{array}{l}\text { Change in participants' } \\
\text { reflexivity and behavior }\end{array}$ \\
\hline
\end{tabular}

Reed et al. (2010): "a change in understanding that goes beyond the individual to become situated within wider social units or communities of practice through social interactions between actors within social networks." We consider a change in understanding between individuals as an important first step in this process, and we believe the nature of understanding is not homogeneous. Therefore, we focus on individuals and three dimensions of their understanding: of facts and values (cognitive), of other people (relational), and of the nature of knowledge and how we obtain it (epistemic). Our research questions were the following: (1) In a workshop setting designed to enable social learning processes, do individual participants demonstrate changes in cognitive, relational, and/or epistemic understanding?; (2) What are the topics of learning? Insights gained from a record of cognitive, relational, and epistemic positions and changes in understanding, coupled with specific topics of learning, will inform more comprehensive planning and decision-making processes for environmental management and governance.

\section{Social learning in natural resource management literature}

Research in natural resource management and the roles of citizens and stakeholders has increasingly examined social learning throughout the last decade (e.g., Pahl-Wostl 2006, Steyaert and Jiggins 2007, Berkes 2009, Leach et al. 2014, Beers et al. 2016, Benson et al. 2016). However, social learning research remains a mix of unstandardized conceptual and theoretical foundations, epistemological lenses, and methodological approaches (Rodela 2011, 2013, Cundill and Rodela 2012, Rodela et al. 2012). In practice, social learning is a normative goal for both process and outcome of adaptive and collaborative management (Reed et al. 2010), yet clear documentation that a certain type of learning has occurred among individuals or groups is often lacking (Armitage et al. 2008, Rodela 2013). Recently, social learning scholars published a series of reviews to synthesize previous social learning research (Lotz-Sisitka 2012), thus enabling scholars to situate future research in clear domains of natural resource management literature, theoretical foundations, research perspectives, and methodological approaches. The following sections invoke these domains to explain how this study fits within, and contributes to, social learning scholarship.

\section{Social learning processes and outcomes across management paradigms}

Social learning has emerged as a prominent concept in three primary domains of environmental and natural resource management literature: adaptive management, collaborative management, and adaptive comanagement (Cundill and Rodela 2012). Cundill and Rodela (2012) found that ideas about social learning processes and outcomes have developed from these paradigms in five ways, two of which are our focus here: (1) social learning takes place through deliberative processes involving sustained interaction between individuals, and the sharing of knowledge and perspectives in a trusting environment (process), and (2) social learning improves decision making by increasing awareness of human-environment interactions and by building relationships and the problem-solving capacity of stakeholders (outcome; Cundill and Rodela 2012). Our investigation is designed around the assumption that social learning takes place through deliberative processes that, in turn, improve decision making by increasing awareness of human-environment interactions. As such, this study aligns with the collaborative management paradigm as presented by Cundill and Rodela (2012).

Within collaborative management literature, scholars assert that social learning is usually triggered by inclusiveness, extended engagement, opportunities for information exchange, opportunities for dialogue and interaction, opportunities for participants to define and control the agenda, open communication, and equal participation (Muro and Jeffrey 2012). These conditions for a social learning process, also found in collaborative management literature, serve as criteria for effective or successful collaborative management processes (Conley and Moote 2003, Schusler et al. 2003; Fig. 1).

Yet Delli Carpini et al. (2004:320) highlight benefits and pitfalls of deliberative processes: while deliberation is "expected to lead to empathy with the other...through an egalitarian, open-minded 
and reciprocal process of reasoned action," deliberation can also be "infrequent, unrepresentative, and disconnected from actual decision-making" making it an "impractical mechanism for determining public will." To make claims about tangible outcomes of a social learning process and whether they are positive or negative, we must first document the occurrence of social learning and explain the context in which it was observed (Rodela 2013).

\section{Research perspectives for social learning and theoretical foundations}

Aside from theorizing how social learning processes lead to social learning outcomes, past investigations have built upon an array of theoretical foundations that support distinct branches of research perspective including different variables of social learning and levels of analysis (Rodela 2011, 2013). Rodela (2011, 2013) identified three social learning research perspectives: individual-centric, network-centric, and systems-centric.

Our investigation fits in an individual-centric approach to understanding social learning based on the theory of communicative action. Communicative action is a process of interactions between two or more individuals who aim for shared understanding of a situation (Habermas 1984). Social learning occurs where there are interactions, deliberations, and knowledge coproduction among stakeholders (Steyaert et al. 2007, Reed et al. 2010). Habermas (1984) developed the theory of communicative action to explain how those multiple interactions between individuals affect social systems through language, relations to the social world, and claims of speech validity, i.e., is a statement true, correct, or sincere. Interactions and critical thinking through participatory processes and integration of different knowledge can lead to changes in participants' cognition or knowledge (Schneider et al. 2009). Arguably, by examining communication and interactions between participants, we might observe how social learning processes enable changes in individuals' knowledge and transform shared understanding into collective action (Pahl-Wostl and Hare 2004, Rist et al. 2006). In this vein, social learning occurs in the "public sphere" of a deliberative democracy, which can take the form of public engagement in collaborative natural resource management.

Within the domain of collaborative management, individualcentric social learning research has relied on tenets of deliberative democracy to locate and observe social learning processes and outcomes. What established theory can inform our observation of stakeholder dialogue, especially in settings where diverse groups and contested views are represented? Applicable variables and their definitions vary widely in this area of social learning research. In her extensive review of social learning in natural resource management literature, Rodela (2013) found evidence for authors' borrowing of the term social learning from behavioral psychologist Albert Bandura, but no borrowing of his posited and supported theoretical relationships between cognition and behavior or other theories of psychology to inform frameworks or analysis. Dimensions of social learning are defined in various ways throughout the literature with common variables identified and listed in Table 1. This study imports ideas from communication and psychology on question-answer learning through conversational agents (Graesser et al. 1993, 2014) to inform the analytical strategy, and includes the little-studied epistemic dimension in the conceptual framework of social learning variables (Table 1).

Table 1. Common dimensions and variables of social learning to be applied in this investigation; drawn from Blackmore (2007), Muro and Jeffrey $(2008,2012)$.

\begin{tabular}{ll}
\hline \hline $\begin{array}{l}\text { Dimension } \\
\text { of Social } \\
\text { Learning }\end{array}$ & Variables \\
\hline Cognitive & $\begin{array}{l}\text { Knowledge of facts, values } \\
\text { Identification of factors contributing to management } \\
\text { problem }\end{array}$ \\
& $\begin{array}{l}\text { Knowledge of alternative actions } \\
\text { Perceptions of others } \\
\text { Relational }\end{array}$ \\
& $\begin{array}{l}\text { Expressions of trust, trust building } \\
\text { Identification of opportunities to work together } \\
\text { Eays of knowing } \\
\text { Claims of validity and justification for knowledge }\end{array}$ \\
\hline
\end{tabular}

\section{METHODS}

\section{Data collection}

To investigate dimensions of social learning in a deliberative setting, we observed stakeholder dialogue among participants in five workshops coordinated for the Bruneau-Owyhee SageGrouse Habitat Project (BOSH) in Owyhee County, Idaho, USA. In the fall of 2013, the Boise District Office of the federal Bureau of Land Management (BLM) proposed a plan to remove juniper (Juniperus spp.) from low-elevation areas in order to conserve habitat for the Greater Sage-Grouse (Centrocercus urophasianus), at the time, a candidate species for listing under the Endangered Species Act. Over the span of two months in the spring of 2014, we conducted workshops designed to achieve the BLM's objectives for engaging stakeholders in a supplementary scoping process while drafting an Environmental Impact Statement (EIS). The purpose of the workshops was to identify spatial distributions of socio-cultural, economic, and ecological place meanings across Owyhee County and the BOSH project area (Fig. 2), and to assess potential social-ecological impacts from four proposed alternatives for removing juniper (Bentley Brymer et al. 2016). The workshops also enabled us to observe stakeholders in a deliberative setting and to assess their discussions for evidence of social learning.

Prior to our agreement with the BLM, a BOSH working group had been formed by the EIS project lead and comprised conservationists, wildlife biologists, a restoration coordinator, an archaeologist, a natural resource manager, a land management supervisor, and one individual who did not self-identify an occupation (Group 1). Some of these group members were professional colleagues within the same agency or across agencies with a history of collaboration on resource management plans. Given the strong representation of land and resource managers in Group 1, we developed a sampling frame using a list of organizations involved in the Owyhee Initiative, a long-term collaborative effort whose members are concerned with ecosystem functions and public lands management across Owyhee County (http://owyheeinitiative.org). We then purposively sampled 27 stakeholder groups to broaden the range of groups and 
Table 2. Organizations represented by workshop participants compared across workshop groups and activities.

\begin{tabular}{|c|c|c|}
\hline & Group 1 & Group 2 \\
\hline $\begin{array}{l}\text { Workshop } 1 \\
\text { Questionnaires, discussion, and deliberation }\end{array}$ & $\begin{array}{l}\text { The Nature Conservancy; Trout Unlimited; } \\
\text { Pheasants Forever; Bureau of Land } \\
\text { Management; National Resource Conservation } \\
\text { Service; Idaho Fish and Game; Owyhee County } \\
\text { Sage-Grouse Local Working Group } \\
(\mathrm{n}=12)\end{array}$ & $\begin{array}{l}\text { Idaho Conservation League; National Resource } \\
\text { Conservation Service; All-Terrain Vehicle } \\
\text { recreation club; Audubon Society; Privately } \\
\text { owned cultivation and restoration company (n = } \\
\text { 5) }\end{array}$ \\
\hline $\begin{array}{l}\text { Workshop } 2 \\
\text { Mapping(a) }\end{array}$ & $\begin{array}{l}\text { Trout Unlimited; Pheasants Forever; Bureau of } \\
\text { Land Management; National Resource } \\
\text { Conservation Service; Owyhee County Sage- } \\
\text { Grouse Local Working Group }(n=6)\end{array}$ & $\begin{array}{l}\text { All-Terrain Vehicle recreation club; County } \\
\text { commission/livestock industry }(n=2)\end{array}$ \\
\hline $\begin{array}{l}\text { Workshop } 2 \\
\text { Mapping(b) }\end{array}$ & & $\begin{array}{l}\text { Audubon Society; Range management/livestock } \\
\text { industry } \\
(\mathrm{n}=2)\end{array}$ \\
\hline
\end{tabular}

perspectives represented in the workshops. This enabled us to create a second workshop group comprising people with little to no previous involvement with the BOSH project (Group 2). Members of Group 2 included conservationists, a county commissioner, a range specialist, a cartography technician, a selfemployed person, and a retired fire-fighter. Members of both groups also self-identified the organization(s) they represented during the workshop activities (Table 2). Group 1 included 12 members (with six repeat participants) generally representing land and resource management, conservation, and wildlife biology, and Group 2 included seven members (with two repeat participants) generally representing conservation, recreation, agriculture, and livestock operations.

Fig. 2. Owyhee County, Idaho and the Bruneau-Owyhee SageGrouse Habitat (BOSH) project area boundaries.

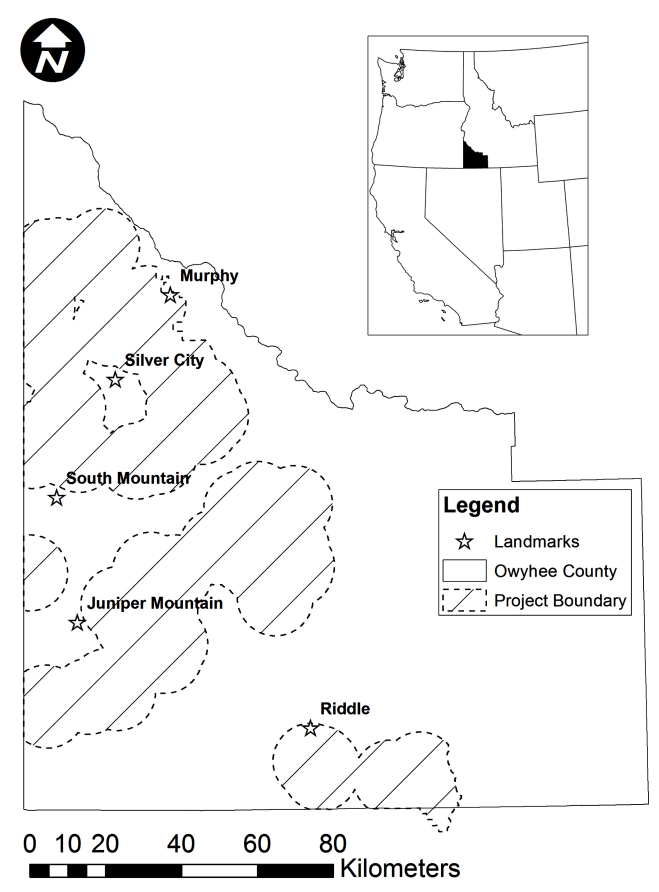

Each group was invited to participate in a two-workshop series; Workshop 1 involved questionnaires, discussion, and deliberation of treatment alternatives, and Workshop 2 involved participatory mapping activities. When participant turnout was low for Group 2 Workshop 2, we scheduled a repeat participatory mapping workshop (Workshop 2b) to extend participation and increase perspectives for the social-ecological impact assessment (Table 2). This resulted in a total of five workshops that were conducted from mid-March to mid-May 2014. Each workshop lasted an average of five hours. We followed ethical guidelines for working with human subjects, and the University of Idaho Institutional Review Board approved our project (\#12-357).

For both groups, Workshop 1 began with a presentation by the $\mathrm{BOSH}$ project lead describing the proposed juniper removal alternatives. The presentation was followed by four rounds of questionnaires and related discussions prompting participants' perceptions of future scenarios under the four proposed juniper treatment alternatives. Workshop $2 \mathrm{a} / 2 \mathrm{~b}$ involved two participatory mapping exercises to identify the spatial distribution of place meanings across Owyhee County and the $\mathrm{BOSH}$ project area and to identify areas where participants did not want to see juniper removed. All workshops were audiorecorded and transcribed for analysis in NVivo 10 (QSR International Pty Ltd. Version 10, 2012, Burlington, MA).

\section{Data analysis}

Research in communication and psychology suggests that verbal, active inquiry with conversational agents enables the acquisition of knowledge (Graesser et al. 1993, 2014). In other words, when we ask questions and receive answers, we learn. This theoretical line of thinking informs our analysis of stakeholder dialogue for evidence of social learning.

We employed three analytical techniques to examine the qualitative data and illuminate social learning as our theoretical construct of interest: cross-case pattern, deductive, and content analyses (Patton 2015). First, the dialogue observed in each of the five workshops, or cases, was analyzed for patterns of communication and interactions between participants, researchers, and the facilitator, and compared across cases. Next, we deductively coded the observed patterns of communication to illuminate the theoretical construct that frames our investigation, i.e., social learning. Finally, we analyzed the workshop dialogue 
Fig. 3. The number of stakeholder statements and question-answer exchanges (by coding reference count; $\mathrm{Y}$ axis) across all workshop groups and activities ( $\mathrm{X}$ axis) that demonstrated cognitive, relational, or epistemic positions and opportunities for cognitive, relational, and epistemic changes in understanding ( $Z$ axis). No opportunities for epistemic change in understanding were observed.

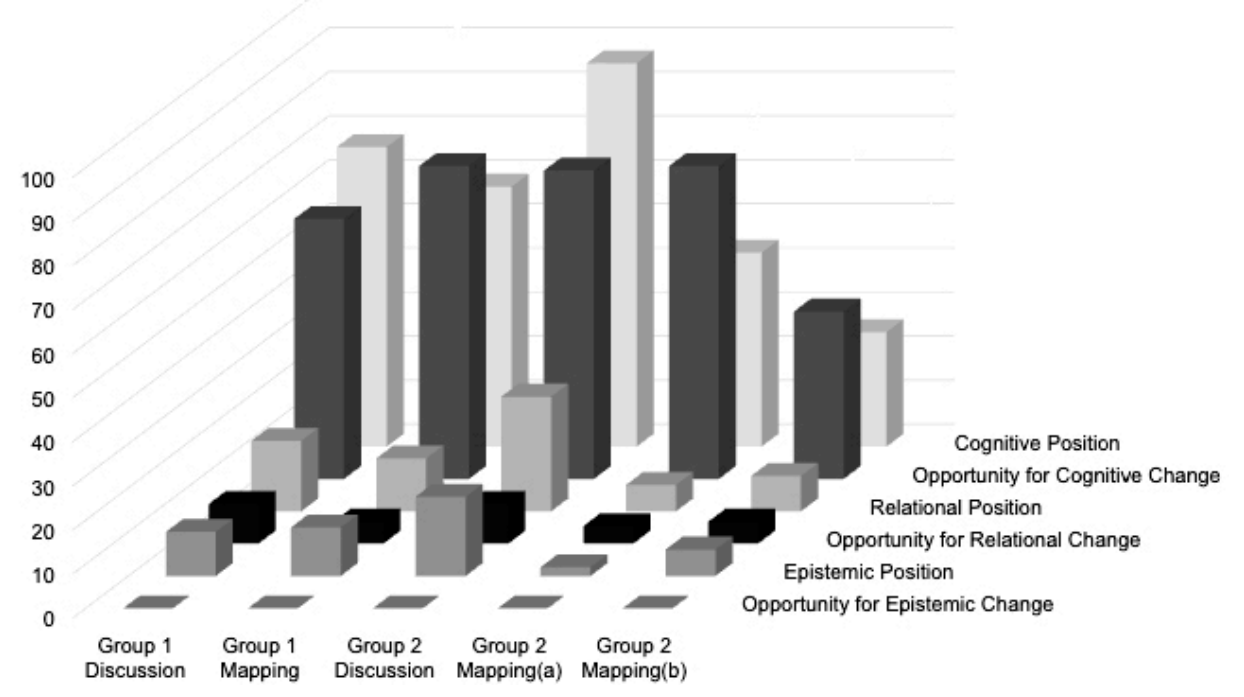

for content by identifying and categorizing the topics of discussion and, potentially, of learning (Patton 2015). Each step in our analysis is further described below.

\section{Cross-case patterns}

The first round of coding revealed similar patterns of communication and interaction across all five workshops, including specific patterns of speech: general statements and question-answer exchanges. General statements were coded as positions, or the current state of individuals' understanding. Question-answer exchanges were coded as opportunities for change in individuals' understanding. Thus, the unit of analysis for the subsequent deductive approach was patterns of speech, specifically general statements and question-answer exchanges.

\section{Deductive analysis}

Predetermined dimensions of social learning (Table 1) guided our second round of coding to further illustrate the positions and opportunities for changes in understanding revealed in the workshop dialogue. When a participant shared information, opinions, or values to explain their knowledge and understanding of a discussion topic, the statement was coded as cognitive position. When a participant shared a perception of other workshop participants or of other people involved in juniper or Sage-Grouse issues, or when they identified opportunities to collaborate or to build-trust with others (or not), the statement was coded as relational position. When a participant shared or described their way of knowing, e.g., observation or intuition, or described a process that generated knowledge and understanding, the statement was coded as epistemic position.

We then focused on question-answer exchanges between two or more participants. When a participant asked a question to acquire new information or to clarify details regarding a discussion topic, the exchange between the participant questioning and the participant(s) answering was coded as opportunity for cognitive change. When a participant asked a question of another participant about his or her experiences, perspective, community connections, or interest in collaborating, the question-answer exchange was coded as opportunity for relational change. Finally, when a participant asked a question about another participant's source of information or justification for a belief, the questionanswer exchange was intended to be coded as opportunity for epistemic change.

\section{Content analysis}

To identify the topics of discussion, we inductively identified and categorized the subject content of all data coded as opportunities for cognitive, relational, or epistemic change. In other words, we categorized the topics that were being discussed during questionanswer exchanges.

\section{FINDINGS}

Evidence of social learning in workshop dialogue

We observed workshop participants making statements indicative of cognitive, relational, and epistemic positions across all groups and workshops (Fig. 3). Although these statements are important for forming explanations of knowledge, our main interest is in the question-answer exchanges that signal opportunities for cognitive, relational, and epistemic change. In the interest of generating substantive insight, we will present and discuss the meaning of the frequencies of statements and question-answer exchanges related to each dimension of learning. To be clear, we are deconstructing the term "social learning" into three relevant parts, cognitive, relational, and epistemic understanding, to document and make meaning out of their presence (or absence) in stakeholder dialogue. 


\section{Comparison of three dimensions}

The cognitive dimension of social learning was the most frequently observed, including both cognitive position and opportunities for cognitive change (Fig. 3). Together, the combined stakeholder dialogue from all five workshops revealed more question-answer exchanges signaling opportunities for cognitive change (309) than individual statements indicating cognitive positions (284). This means that it was more common for a workshop participant to engage in question-exchanges and thus learn than to make factual or value statements.

The relational dimension of social learning was observed far less than the cognitive dimension (Fig. 3). Statements indicating a relational position (e.g., "Yeah, there's a lot of ignorance out there about how all of this works and how things get done.") were more common than question-answer exchanges indicating opportunity for relational change (e.g., Question: "Would it be okay if maybe I get contact information for everybody so we can sit down sometime, figure out where we coincide with each other and maybe where we butt heads?" Answer: "Yes, does someone have a piece of paper?"). This means that it was more common for a workshop participant to describe their perceptions of other people or to express trust (or lack of it) in other people than to ask-answer another workshop participant about their life or work or to identify opportunities to work together.

The epistemic dimension of social learning was the least observed across all groups and workshop activities (Fig. 3). Statements indicating an epistemic position were observed, for example:

... it just makes me realize that we don't know, and so we're studying like God to fix this landscape that's been here a lot longer than we have, and it was functioning before we got here, and maybe we can step back a bit and study it up a little bit more.

Using a strict criterion for observing opportunities for epistemic change, we did not observe question-answer exchanges about epistemic orientation (e.g., "How do you know that is true?, How did you acquire that information?, Can you justify that position?") or descriptions of a changed way of knowing as a result of conversing with another workshop participant. In other words, no participant challenged another for sources or additional information to support their claims. We might assume this lack of question-answer exchange about sources and methods for gaining knowledge is due to individual personalities, group dynamics, or a collaborative history among group members. However, we did not observe opportunities for epistemic change in either pre-existing Group 1 or newly formed Group 2.

Comparison of social learning dimensions across groups and activities

Upon coding and comparing the frequency of question-answer exchanges for all three dimensions of social learning across all workshops, there is little discernable or meaningful difference between the first four workshops (Group 1 Discussion, Group 1 Mapping, Group 2 Discussion, and Group 2 Mapping[a]), with some minor exceptions (Fig. 3). First, participants in the more homogeneous Group 1 Discussion Workshop engaged in fewer cognitive question-answer exchanges than participants in the Group 1 Mapping, Group 2 Discussion, and Group 2 Mapping (a) workshops. This means participants in the Group 1 Discussion workshop were less likely to experience opportunities for cognitive changes in understanding. This could be partly due to the professional roles of many Group 1 Discussion participants: as public lands and natural resource managers, several had some prior awareness of the BOSH project. For example, participants in those workshops asked fewer questions about the socialecological dynamics of the Owyhee region or about Sage-Grouse habitat problems. There is not much to ask about or learn when everyone in the room knows the answers.

A second minor exception to the general pattern of dialogue across the three dimensions relates to more opportunities for relational change for participants in Group 1 Discussion and Group 2 Discussion workshops. Participants in the Discussion workshops engaged in slightly more opportunity for relational change than participants in any of the Mapping workshops. This can be explained in part by some gregarious participants' questions that lead the conversations into more relational domains several times throughout the discussion workshops. Also, the conversational nature of the discussion and deliberation activities was more conducive to learning about others than the mapping activities.

Across all Mapping workshops (Group 1 Mapping, Group 2 Mapping[a], and Group 2 Mapping[b]), we observed more opportunities for cognitive change than cognitive positions (Fig. 3). In other words, participants of mapping activities asked, answered, and learned far more than they stated facts or values. This can be explained by the nature of the participatory mapping activity: workshop participants stood around each map and asked more questions of each other on the same topics (e.g., spatial orientation: "Is this Murphy?," "Is that where the trail exits onto Mud Flat Road?," "Where do you stop to gas up your ATV?").

Participants in Group 2 Mapping(b) appear to have engaged in meaningfully less opportunity for cognitive or relational changes than any of the other groups or workshops (Fig. 3). This can be explained by a few factors. Although members of Group 2 Mapping(b) were civil toward each other on most topics, they generally held opposing viewpoints. A participant in the Group 2 Mapping(b) workshop rarely spoke during the mapping exercise, even when prompted by researchers and the facilitator. Less dialogue translated to fewer opportunities for questionanswer exchanges, explanation, argumentation, or learning (Graesser 1993). Also, a participant in the Group 2 Mapping(b) workshop did not want to see any juniper removed from the landscape, so this participant did not draw any polygons on any maps during the Group 2 Mapping(b) workshop. When other participants took 10-20 minutes drawing and explaining their values and place meanings across the maps of Owyhee County and the BOSH project area, the participant who did not want any juniper removed explained:

Participant 1:

"It just gives me peace of mind knowing that there's some place on the planet that we could all disappear and that place would be fine; would probably be better for it."

Participant 2:

"Are there any areas outside of wilderness that you feel that away about?" 
Table 3. Topics of discussion during dialogic interactions that signaled opportunities for individuals' cognitive and relational change. No opportunities for epistemic change were observed. BOSH = Bruneau-Owyhee Sage-Grouse Habitat Project; NEPA = National Environmental Policy Act; SEIA = social-ecological impact assessment.

\begin{tabular}{|c|c|c|c|c|c|}
\hline & \multicolumn{2}{|c|}{ Discussion Workshops } & \multicolumn{3}{|c|}{ Mapping Workshops } \\
\hline & Group 1 & Group 2 & Group 1 & Group 2a & Group 2b \\
\hline \multirow[t]{7}{*}{ Cognitive change } & $\mathrm{BOSH}$ & BOSH & BOSH & BOSH & BOSH \\
\hline & NEPA & & & & \\
\hline & Ecosystem services & Ecosystem services & Ecosystem services & Ecosystem services & Ecosystem services \\
\hline & Social processes & & Social processes & Social processes & Social processes \\
\hline & & & Owyhee region & Owyhee region & Owyhee region \\
\hline & & $\begin{array}{l}\text { Values and place } \\
\text { meanings }\end{array}$ & $\begin{array}{l}\text { Values and place } \\
\text { meanings }\end{array}$ & $\begin{array}{l}\text { Values and place } \\
\text { meanings }\end{array}$ & $\begin{array}{l}\text { Values and place } \\
\text { meanings }\end{array}$ \\
\hline & Workshop activities & & Workshop activities & Workshop activities & Workshop activities \\
\hline \multirow[t]{2}{*}{ Relational change } & $\begin{array}{l}\text { Perceptions of others } \\
\text { (within and outside } \\
\text { workshop) }\end{array}$ & $\begin{array}{l}\text { Perceptions of others } \\
\text { (within and outside } \\
\text { workshop) }\end{array}$ & $\begin{array}{l}\text { Perceptions of others } \\
\text { (within and outside } \\
\text { workshop) }\end{array}$ & $\begin{array}{l}\text { Perceptions of others } \\
\text { (within workshop) }\end{array}$ & $\begin{array}{l}\text { Perceptions of others } \\
\text { (within workshop) }\end{array}$ \\
\hline & $\begin{array}{l}\text { Opportunity for field } \\
\text { trips, to share research } \\
\text { and papers, to work } \\
\text { with BOSH critics, to } \\
\text { continue SEIA } \\
\text { workshops }\end{array}$ & $\begin{array}{l}\text { Opportunity to work } \\
\text { together on other } \\
\text { projects }\end{array}$ & $\begin{array}{l}\text { Opportunity to work } \\
\text { with / to not work with } \\
\text { BOSH critics }\end{array}$ & $\begin{array}{l}\text { Opportunity to stay } \\
\text { connected }\end{array}$ & \\
\hline Epistemic change & (none) & (none) & (none) & (none) & (none) \\
\hline
\end{tabular}

Participant 1:

"Oh sure, I feel that way about the whole planet, actually."

In this example, Participant 2 asked a question about the opinion of Participant 1, and Participant 1 answered with clarifying information, thus presenting an opportunity for Participant 2 to have a change in understanding about the opinions and values of Participant 1 . This is distinct from an opportunity for relational change because, as explained above, that is demonstrated by verbalizations of trust and question-answer exchanges about opportunities to work together. It is also distinct from an opportunity for epistemic change signaled by question-answer exchanges about ways of knowing and processes that generate knowledge and understanding.

\section{Social learning topics}

Given the structured design of the workshop questionnaires and the semistructured design of discussion and mapping activities, participants conversed about several similar topics in all five workshops (Table 3). For example, participants exchanged questions and answers about the BOSH project and ecosystem services during all five workshops. Interestingly, question-answer exchanges about the National Environmental Policy Act (NEPA) and its requirements for EIS only occurred during the Group 1 Discussion workshop. In other words, participants in that workshop were the only stakeholders to experience opportunities for cognitive changes in understanding about administrative law. This finding is explained in part by the attribute of Group 1 as a more homogenous set of land and resource managers accustomed to working under NEPA and drafting EIS. Recreationists, conservationists, and ranchers in Group 2 did not query each other about NEPA timeline, process, or analysis.

In all groups across all workshops, participants discussed their perceptions of each other (Table 3). Participants in the Group 1 Discussion, Group 1 Mapping, and Group 2 Discussion workshops also shared their perceptions of outsiders, or stakeholders related to the BOSH project and to the Owyhee region that did not participate in our workshops. In particular, conversation among the 12 members of the Group 1 Discussion workshop centered on extreme alternative views that were perceived to exist outside and in opposition to views expressed and shared among members of Group 1. It seemed that shared negative views of "the other" emerged in the Group 1 Discussion and Group 1 Mapping workshops that may have reinforced trust between like-minded individuals. It is unclear if the maintenance of this kind of like-minded trust is a causal mechanism for social learning outcomes like collective action (collective among whom?) or for changes in resource management (for whom?).

Finally, members of Group 2 Mapping(b) were the only participants that did not articulate opportunities to work together or stay connected (Table 3). Granted, this group included only two people: a range specialist sympathetic to the livestock industry, and a representative of the Audubon Society sympathetic to environmentalist and preservationist principles. Even so, they engaged in a pattern of dialogue similar to the other four workshops, covering mostly cognitive, some relational, and few epistemic dimensions.

These two stakeholders were civil and agreed to disagree, but they did not discuss opportunities to collaborate or keep in touch. What was said, however, was in response to the facilitator's question: "What have you learned about each other after working through this workshop together?" One participant replied, "Well, I learned that he's not so bad after all." Although evidence for outcomes like common ground and collaborative relationships was not observed in this group, this question-answer exchange illuminates relational change as an intriguing and potentially critical dimension of social learning. 


\section{DISCUSSION}

Illumination of social learning dimensions at the individual scale According to Reed et al. (2010), social learning is a change in understanding that goes beyond the individual to become situated within wider social units or communities of practice through interactions between actors within social networks. We focus on the first step in that process, changes in understanding within and between individuals in a group setting, and build on established dimensions of social learning. The epistemic dimension is an explicit element of stakeholder dialogue that was analyzed alongside cognitive and relational dimensions. Across our five workshop cases, we observed individuals' statements demonstrating cognitive, relational, and epistemic positions, and we observed question-answer exchanges between individuals that indicated opportunities for change in cognitive and relational understanding.

\section{Frequency and meaning}

There seemed to be a key difference between the number of question-answer exchanges and the perceived importance of those interactions. Interestingly, when prompted to openly reflect on their workshop experience after completing the last activity, most participants noted what they had learned about other participants. This underscores an appreciation for relational changes rather than changes in cognitive or epistemic understanding. In other words, although statements and question-answer exchanges about facts, values, and the BOSH project were more frequent, some participants emphasized and described what they learned about other participants and mutually identified opportunities to collaborate the more meaningful workshop experience.

\section{Elusive epistemic change}

Although our analysis of stakeholder dialogue revealed opportunities for cognitive and relational change, we did not observe opportunities for epistemic change. This finding is not surprising when taken into consideration with suggestions that epistemic cognition is not a norm in everyday dialogue, in addition to moral reasoning or conceptual change (Sinatra et al. 2014). Epistemic cognition has been used recently as "an umbrella term for the beliefs people hold about the nature of knowledge and knowing and the application and influence of such beliefs when considering scientific and socio-scientific everyday problems" (Sinatra et al. 2014:126 [emphasis in the original]). In other words, people do not always cite their sources in everyday conversations.

In social learning contexts, when people are conversing from diverse epistemic positions, testimony is a central means of learning. Each person must evaluate the reliability of the testimony based on the structure and source of knowledge, and on justification for knowing, i.e., authority or expertise. Before accepting or adopting new knowledge, it stands to reason that learners are filtering that knowledge through epistemic cognition and weighing the testimony against their own ways and justifications for knowing. However, our understanding of epistemic positions and opportunities for change in epistemic understanding are limited when an individual's epistemic cognition is not verbalized (or normalized) through dialogue. Although research in the area of epistemic cognition has advanced somewhat in education fields, applications to natural resources remain limited and underdeveloped thus far.

\section{Setting the stage for social learning between individuals and within groups}

Interactions and activities matter

In comparing the activities of the discussion and mapping workshops, we found that opportunity for relational change occurred more often during the discussion workshops than in the mapping workshops, but not significantly so. This is not surprising given the one-on-one nature of the mapping activity between participant and facilitator with little opportunity for participants to interact with each other. Kwok et al. (2000) theorized that intentional and meaningful subject feedback in a collaborative learning group promotes assimilation of new information, which in-turn stimulates learner interaction and promotes accommodation of new information to restructure one's worldview. This evokes a "chicken or egg - which came first?" analogy: does one assimilate new information to enhance interaction, or does one interact to enhance the assimilation of new information? Perhaps social learning has occurred either way and is not contingent on just one sequence. The point here is that interactions create more fruitful opportunities for learning than one-way communication, and this kind of dialogue for decision making is an important mechanism for changing perspectives and (possibly) behavior (Beratan 2007).

Our mapping activities were semistructured and participants were invited to speak up with comments or questions at any time. But as each participant took a turn drawing on the map, the dialogue faded and often devolved into one-way communication as participants explained what they were looking at on the map. As described above, there were some question-answer exchanges, though mainly opportunities for cognitive change. This design did not promote intentional feedback between participants, so it did not provide many opportunities for relational change. Findings from literature on boundary objects suggest that a map should enable different groups to work together without consensus (Star 2010) and that it might carry learning potential through actions of identification, coordination, reflection, and transformation (Akkerman and Bakker 2011). Yet these objects and mechanisms for learning are inadequate if the style and direction of communication remains one-way without stimulating learner interactions.

Implications for communication, participation, and management Overall, our evidence aligns with previous claims that, in addition to considering diversity and representation (who is at the table), we should pay more attention to how participants converse, e.g., rounds of questions and answers in a lively environment, or a few quiet exchanges of polar opposite opinions followed by silence. Recently, Beers et al. (2016) established links between the communicative interactions at an individual-scale to real-world action at a network/societal scale by analyzing patterns of interactions in a discursive learning context. After coding for interaction type and tone, Beers et al. (2016) found that antithetic, or "attack-and-defend" patterns of interaction resulted in more substantial learning outcomes than synthetic, or "harmonious" patterns of interaction. Although our investigation was not designed to analyze interaction type or tone, nor connect learning process with outcomes, our findings support the notion that stakeholder dialogue involving diverse epistemic positions, which can perhaps manifest in attack-and-defend patterns of 
interaction, are important for both social learning processes and outcomes. Recalling Habermas's (1984) theory of communicative action, coordinated action is predicated on shared understanding achieved by individuals who interact in ways that include claims of speech validity, i.e., argumentation.

Regarding implications for practice, conventional steps toward satisfying the legal and regulatory requirement of public participation are unlikely to lead to learning. We must consider the nature of interactions and direction of communication before claiming that certain management paradigms support social learning and result in collaborative relationships and collective action. Emphasis should probably be placed on designing activities that create more opportunities for stakeholder dialogue, including question-answer exchanges and constructive argumentation, and on recruitment of a diverse representation of epistemologies, or people with different ways of knowing, e.g., scientific, experiential, spiritual.

\section{CONCLUSION}

\section{Limitations and future research}

As an alternative to surveys or experimental design, this observation-based approach could also be applied post hoc to assess transcripts of dialogue for evidence of individual-scale social learning within decision-making or planning processes. Our analysis of workshop dialogue provides an alternative approach to social learning research that can complement knowledge informed by interview and questionnaire-based approaches.

Our analytical strategy remains limited by the reality that analysis of stakeholder dialogue focused solely on verbal communication. This analysis did not consider participants' tone or attempt to interpret their attitudes toward others. We cannot say for sure who experienced cognitive, relational, or epistemic change: the person who asked the question? The person who answered? Both? Was it a cognitive change for the questioner, but a relational change for the responder? There are probably several dimensions of learning occurring simultaneously. Future research that applies an individual-centric perspective to social learning will benefit from mixed-methods approaches that include both observation of phenomena and a survey of participants' perceptions and reflections of the social learning process. It would be insightful to integrate analyses of stakeholder dialogue and pre-post surveys for self-reflection to triangulate dimensions of learning based on the phenomenon as it occurs in collaborative and adaptive management settings and based on what participants perceive that they learn.

Future research should also endeavor to measure changes in dimensions of social learning beyond the initial social learning process. According to Reed et al. (2010) a one-time assessment of these variables will not demonstrate that social learning has occurred. We find that the social learning process is not as linear as Figure 1 suggests in its two-dimensional and academic format. Learning is a nonlinear, dynamic process, and, as such, not necessarily an aggregation of individuals' question-answer exchanges. There is a need to document cognitive, relational, and epistemic change in individuals and a diffusion of cognitive, relational, and epistemic changes to communities of practice beyond the original locus of learning. This is an area of research that will provide ample opportunity to improve our understanding of causal relationships between social processes and outcomes as mediated by individuals and their actions. Despite numerous claims that social learning processes, e.g., open communication and diverse participation, for natural resource management contribute to or enable collaborative relationships, collective action, and other positive outcomes (Conley and Moote 2003, Schusler et al. 2003), we do not fully understand how learning occurs at the individual scale to influence individual-, network-, and systems-level outcomes. The evidence presented here contributes to furthering an individual-centric conceptualization and definition of social learning that is observable, informs process design, and invokes disciplinary roots for growing a more explanatory social learning theory for collaborative and adaptive management.

Responses to this article can be read online at: http://www.ecologyandsociety.org/issues/responses. php/9959

\section{Acknowledgments:}

We are sincerely grateful to M. McGee, L. Okeson, J. Suhr Pierce, A. Talsma, D. Miller, and N. Rimbey for their guidance, partnership, and willingness to support new, progressive ideas. We thank the National Science Foundation IGERT program (Award 0903479), the Bureau of Land Management ( Award L14AC00060), the Idaho Governor's Office of Species Conservation (Award BOSEIA14), and the University of Idaho Rangeland Center for financial and logistical support. We thank B. Stewart for providing comments that greatly improved this manuscript. Finally, we thank $J$. Holbrook, R. Niemeyer, and A. Suazo for their interdisciplinary vision and collaborative adaptive teamwork.

\section{LITERATURE CITED}

Akkerman, S. F., and A. Bakker. 2011. Boundary crossing and boundary objects. Review of Educational Research 81(2):132-169. http://dx.doi.org/10.3102/0034654311404435

Armitage, D., M. Marschke, and R. Plummer. 2008. Adaptive comanagement and the paradox of learning. Global Environmental Change 18(1):86-98. http://dx.doi.org/10.1016/j.gloenvcha.2007.07.002

Beers, P., B. van Mierlo, and A.-C. Hoes. 2016. Toward an integrative perspective on social learning in system innovation initiatives. Ecology and Society 21(1):33. http://dx.doi. org/10.5751/ES-08148-210133

Benson, D., I. Lorenzoni, and H. Cook. 2016. Evaluating social learning in England flood risk management: an 'individualcommunity interaction' perspective. Environmental Science and Policy 55:326-334. http://dx.doi.org/10.1016/j.envsci.2015.05.013

Bentley Brymer, A. L., J. D. Holbrook, R. J. Niemeyer, A. A. Suazo, J. D. Wulfhorst, K. T. Vierling, B. A. Newingham, T. E. Link, and J. L. Rachlow. 2016. A social-ecological impact assessment for public land management: application of a conceptual and methodological framework. Ecology and Society 21(3):9. http://dx.doi.org/10.5751/ES-08569-210309 
Beratan, K. K. 2007. A cognition-based view of decision processes in complex social-ecological systems. Ecology and Society 12 (1):27. http://dx.doi.org/10.5751/ES-02103-120127

Berkes, F. 2009. Evolution of co-management: role of knowledge generation, bridging organizations and social learning. Journal of Environmental Management 90(5):1692-1702. http://dx.doi. org/10.1016/j.jenvman.2008.12.001

Blackmore, C. 2007. What kinds of knowledge, knowing and learning are required for addressing resource dilemmas?: a theoretical overview. Environmental Science and Policy 10:512-525. http://dx.doi.org/10.1016/j.envsci.2007.02.007

Buck, L., E. Wollenberg, and D. Edmunds. 2001. Social learning in the collaborative management of community forests: lessons from the field. CIFOR, Bogor, Indonesia.

Conley, A., and M. A. Moote. 2003. Evaluating collaborative natural resource management. Society and Natural Resources 16:371-386. http://dx.doi.org/10.1080/08941920309181

Craig, R. K., and J. B. Ruhl. 2014. Designing administrative law for adaptive management. Vanderbilt Law Review 67(1):1-87. http://dx.doi.org/10.2139/ssrn.2222009

Cundill, G., and R. Rodela. 2012. A review of assertions about the processes and outcomes of social learning in natural resource management. Journal of Environmental Management 113:7-14. http://dx.doi.org/10.1016/j.jenvman.2012.08.021

Delli Carpini, M. X., F. L. Cook, and L. R. Jacobs 2004. Public deliberation, discursive participation, and citizen engagement: a review of the empirical literature. Annual Review of Political Science 7:315-344. http://dx.doi.org/10.1146/annurev. polisci.7.121003.091630

Fabricius, C., and G. Cundill. 2014. Learning in adaptive management: insights from published practice. Ecology and Society 19(1):29. http://dx.doi.org/10.5751/ES-06263-190129

Graesser, A. C., M. C. Langston, and W. B. Baggett. 1993. Exploring information about concepts by asking questions. Psychology of Learning and Motivation 29:411-436. http://dx.doi. org/10.1016/S0079-7421(08)60147-4

Graesser, A. C., H. Li, and C. Forsyth. 2014. Learning by communicating in natural language with conversational agents. Current Directions in Psychological Science 23:374-380. http://dx. doi.org/10.1177/0963721414540680

Habermas, J. 1984. The theory of communicative action, Vol. I. Beacon, Boston, Massachusetts, USA.

Kwok, R. C. W., J. Ma, and D. Vogel. 2000. Effect of GSS and facilitation on knowledge restructuring. Page 8 in System Sciences, 2000. Proceedings of the 33rd Annual Hawaii International Conference. January 4. Maui, Hawaii, USA.

Leach, W. D., C. M. Weible, S. R. Vince, S. N. Siddiki, and J. C. Calanni. 2014. Fostering learning through collaboration: knowledge acquisition and belief change in marine aquaculture partnerships. Journal of Public Administration Research and Theory 24(3):591-622. http://dx.doi.org/10.1093/jopart/mut011

Lotz-Sisitka, H., editor. 2012. (Re)views on social learning literature: a monograph for social learning researchers in natural resources management and environmental education. Environmental Learning Research Centre, Rhodes University, Grahamstown, South Africa.

McFadden, J. E., T. L. Hiller, and A. J. Tyre. 2011. Evaluating the efficacy of adaptive management approaches: is there a formula for success? Journal of Environmental Management 92 (5):1354-1359. http://dx.doi.org/10.1016/j.jenvman.2010.10.038

Muro, M., and P. Jeffrey. 2008. A critical review of the theory and application of social learning in participatory natural resource management processes. Journal of Environmental Planning and Management 51:325-344. http://dx.doi.org/10.1080/09640560801977190

Muro, M., and P. Jeffrey. 2012. Time to talk? How the structure of dialogue processes shapes stakeholder learning in participatory water resources management. Ecology and Society 17(1):3. http:// dx.doi.org/10.5751/ES-04476-170103

Pahl-Wostl, C. 2006. The importance of social learning in restoring the multifunctionality of rivers and floodplains. Ecology and Society 11(1):10. http://dx.doi.org/10.5751/ES-01542-110110

Pahl-Wostl, C., and M. Hare. 2004. Processes of social learning in integrated resources management. Journal of Community and Applied Social Psychology 14:193-206. http://dx.doi.org/10.1002/ casp. 774

Patton, M. Q. 2015. Qualitative research and evaluation methods: integrating theory and practice. Sage, Los Angeles, California, USA.

Reed, M. S. 2008. Stakeholder participation for environmental management: a literature review. Biological Conservation 141:2417-2431. http://dx.doi.org/10.1016/j.biocon.2008.07.014

Reed, M., A. C. Evely,G. Cundill, I. Fazey, J. Glass, A. Laing, J. Newig, B. Parrish, C. Prell, C. Raymond, and L. C. Stringer. 2010. What is social learning? Ecology and Society 15(4)r1. http://dx. doi.org/10.5751/ES-03564-1504r01

Rist, L., B. M. Campbell, and P. Frost. 2013a. Adaptive management: where are we now? Environmental Conservation 40 (1):5-18. http://dx.doi.org/10.1017/S0376892912000240

Rist, L., A. Felton, L. Samuelsson, C. Sandström, and O. Rosvall. 2013b. A new paradigm for adaptive management. Ecology and Society 18(4):63. http://dx.doi.org/10.5751/ES-06183-180463

Rist, S., M. Chiddambaranathan, C. Escobar, and U. Wiesmann. 2006. "It was hard to come to mutual understanding ..."- - the multidimensionality of social learning processes concerned with sustainable natural resource use in India, Africa and Latin America. Systemic Practice and Action Research 19:219-237. http://dx.doi.org/10.1007/s11213-006-9014-8

Rodela, R. 2011. Social learning and natural resource management: the emergence of three research perspectives. Ecology and Society 16(4):30. http://dx.doi.org/10.5751/ ES-04554-160430

Rodela, R. 2013. The social learning discourse: trends, themes and interdisciplinary influences in current research. Environmental Science and Policy 25:157-166. http://dx.doi.org/10.1016/j. envsci.2012.09.002 
Rodela, R., G. Cundill, and A. E. Wals. 2012. An analysis of the methodological underpinnings of social learning research in natural resource management. Ecological Economics 77:16-26. http://dx.doi.org/10.1016/j.ecolecon.2012.02.032

Scarlett, L. 2013. Collaborative adaptive management: challenges and opportunities. Ecology and Society 18(3):26. http://dx.doi. org/10.5751/ES-05762-180326

Scarlett, L., and M. McKinney. 2016. Connecting people and places: the emerging role of network governance in large landscape conservation. Frontiers in Ecology and the Environment 14:116-125. http://dx.doi.org/10.1002/fee. 1247

Schneider, F., P. Fry, T. Ledermann, and S. Rist. 2009. Social learning processes in Swiss soil protection - the 'From FarmerTo Farmer' project. Human Ecology 37:475-489. http://dx.doi. org/10.1007/s10745-009-9262-1

Schusler, T. M., D. J. Decker, and M. J. Pfeffer. 2003. Social learning for collaborative natural resource management. Society and Natural Resources 16:309-326. http://dx.doi.

org/10.1080/08941920390178874

Sinatra, G. M., D. Kienhues, and B. K. Hofer. 2014. Addressing challenges to public understanding of science: epistemic cognition, motivated reasoning, and conceptual change. Educational Psychologist 49(2):123-138. http://dx.doi. org/10.1080/00461520.2014.916216

Star, S. L. 2010. This is not a boundary object: reflections on the origin of a concept. Science, Technology, and Human Values 35 (5):601-617. http://dx.doi.org/10.1177/0162243910377624

Steyaert, P., M. Barzman, J. P. Billaud, H. Brives, B. Hubert, G. Ollivier, and B. Roche. 2007. The role of knowledge and research in facilitating social learning among stakeholders in natural resources management in the French Atlantic coastal wetlands. Environmental Science and Policy 10:537-550. http://dx.doi. org/10.1016/j.envsci.2007.01.012

Steyaert, P., and J. Jiggins. 2007. Governance of complex environmental situations through social learning: a synthesis of SLIM's lessons for research, policy and practice. Environmental Science and Policy 10(6):575-586. http://dx.doi.org/10.1016/j. envsci.2007.01.011

Susskind, L., A. E. Camacho, and T. Schenk. 2012. A critical assessment of collaborative adaptive management in practice. Journal of Applied Ecology 49(1):47-51. http://dx.doi. org/10.1111/j.1365-2664.2011.02070.X

Walker, P. A. and P. T. Hurley. 2004. Collaboration derailed: the politics of "community-based" resource management in Nevada County. Society and Natural Resources 17(8):735-751. http://dx. doi.org/10.1080/08941920490480723 